\title{
Theoretical and Methodological Basis of Inclusive Education in the Researches of Russian Scientists in the First Quarter of 20th Century (P. P. Blonsky, L. S. Vygotsky, V. P. Kaschenko, S. T. Shatsky)
}

\author{
Daniya Z. Akhmetova ${ }^{1}$, Tatyana A. Chelnokova ${ }^{1} \&$ Ilona G. Morozova $^{1}$ \\ ${ }^{1}$ Kazan Innovative University named after V. G. Timiryasov, Kazan, Russian Federation \\ Correspondence: Daniya Z. Akhmetova, Kazan Innovative University named after V.G. Timiryasov, Kazan city, \\ zip code 420111, 42 Moscovskaya str., Russian Federation. Tel: 7-843-231-9290. E-mail: ahmetova@ieml.ru
}

Received: October 16, 2016

Accepted: November 25, 2016

Online Published: January 30, 2017

doi:10.5539/ies.v10n2p174

\author{
URL: http://dx.doi.org/10.5539/ies.v10n2p174
}

\begin{abstract}
Article is devoted to the scientific heritage of educators and psychologists of Russia in the first quarter of the twentieth century. The aim of the research is the identification of the most significant ideas of P. P. Blonsky, L. S. Vygotsky, V. P. Kacshenko, S. T Shatsky which based the theoretical and methodological basis of inclusive education. The article describes a number of provisions that have conceptual value and practical importance for the implementation of inclusive education

Keywords: scientific heritage of the first quarter of the twentieth century, inclusive education, children with disabilities, pedagogical anthropology, integrated approach to the study of the child, pedology, social environment, didactic concept of inclusive education, child study, cultural and historical concept
\end{abstract}

\section{Introduction}

Transformations in the training and education of people with disabilities which started at the beginning of the twenty-first century are based on the theoretical heritage of the past. A great contribution to the development of scientific basis of training and education of children with mental and physical development was made by Russian scientists. The scientific heritage of Behterova and Blonsky (1997), Vygotsky (1993), Kashchenko (1994), Troshin (2008), Rossolimo (1914), and of other researchers is of great interest for the formation of conceptual approaches to the organization of successive models of inclusive education.

The history of the researches in the field of inclusive education has not been so deeply discussed in the works of Russian and foreign scientists. Inspitev this fact there are some works of American (Maryland Coalition for inclusive education), Namibian scientists (Rossing Foundation, Khomasdal, Windhoek, Namibia), English scientists (University of New Hampshire), which study the history of inclusive education. The observation of the researches in this field in this article will help us to deeply understand the ideas of inclusive education, the tendency of its development in the works of Russian scientists especially.

The main approach to our research is a historical review of the researches in the field of inclusive education. The main task of research is to study the theoretical and methodological basis of inclusive education in the researches of such Russian scientists in the first quarter of 20 century as P. P. Blonsky, L. S. Vygotsky, V. P. Kacshenko, S. T. Shatsky.

\section{Method}

In the research the following methods were used: methods of theoretical research, method of comparative historical analysis, which allowed comparing different scientific works and their contribution to the field of inclusive education. We also used the methods of induction and deduction, narrative method, historical method, method of periodization. The typological method was also used in the research and it allowed to identify groups of similar phenomena and processes in the researches of inclusive education. The narrative method helped to study cause-and-effect relationship, the findings of facts in the research area.

\section{Anthropological Approach}

A special place in methodological and theoretical foundations of inclusive education should be given to the ideas of educational anthropology. Pedagogical anthropology is an independent field of pedagogical science, 
integrative knowledge of a child as of a whole human being. Integrated knowledge of the child is especially necessary when it concerns joint training of different children.

The ideas of pedagogical anthropology which were developed in the theoretical and practical activities of the greatest Russian scientists in the first quarter of the twentieth century, were laid in the fundamental work of K.D. Ushinsky "Man as the subject of education. Experience of pedagogical anthropology "(the first volume was published in 1868) (Ushinsky, 1945). Ushinsky's idea was that "it is possible to educate a man in all aspects only through recognizing him in all aspects". This idea was reflected in the studies of the last century.

The essence of the anthropological approach to education is in understanding the integrity of each child based on a comprehensive knowledge about the formation of the human being in a man. An integrated approach lies at the basis of the idea of inclusive education. Its implementation in practice of educational institutions supposes the understanding and dialectical development of the main provisions of pedagogical anthropology of the last century in the theory and methodology of inclusive education.

To know the child in the family, in society, at all ages, to know the child in health and sickness, in sorrow and joy - was the requirement developed in the works of Russian anthropologists of the late nineteenth and the first quarter of the twentieth centuries (Ushinsky, Lesgaft, Kapterev, etc.). "We need to know the child - to know more and better than we know the machines with which we work", - wrote Kashchenko (1994). «First we need to consider the child as a whole person, then explore one's features» - wrote Vygotsky (1931). The principles of integrity and development were laid by L. S. Vygotsky in the base of pedology. They were specified in terms of "pedological integrity and pedological development concept covering all aspects of child development in their synthesis" (1993).

An outstanding Russian psychiatrist, neurologist, physiologist, psychologist Bekhterev (1907) performed the idea of considering a person in his/her integrity based on the interdisciplinary interaction. He was a supporter of an integrated approach to the study of man. The important idea of V. M. Bekhterev was that it is impossible to analyze only the individual human behavior, it is necessary to examine the relationship of his/her behavior with the behavior of other people. According to this thinking it is necessary to objectively study a broad range of mutual relations (child with disabilities - healthy peers, the child - parents, teacher - child, the parents of a child with disabilities - parents of healthy children, etc.). Only while studying the relationship of the behavior of children with disabilities with other participants of educational process it is possible to implement an integrated approach to the study of "special" training system of inclusive education.

Sikorsky (1842-1919 years) was one of the first Russian scientists who made the first anthropological study of education and training of children mental and physical disabilities. Scientists paid great attention to the medical, psychological and pedagogical study of a person who had developmental disorders. He was the first who used an experimental method for monitoring mental activities of pupils in schools (Sikorsky, 1882). The main point of this method is that he could observe the mental work of pupils during their educational process and it became further the basis of experimental pedagogy. Today Sikorsky's ideas are very important for the study of teaching all children, even those who are considered to be unteachable.

The fundamental work of G.Y. Troshin (1874-1938 years) "Anthropological basiss of education. Comparative psychology of normal and abnormal children" was published in 1915. The researcher defends the need to find unused resources for the education of the physiological, psychological and social nature of man. G.Y. Troshin (1915) presented the hypothesis that during the practice of working with children with disabilities it is necessary to focus not on the child's defect, but on his/her potential, which are not affected by the disease. Title to this assumption in modern teaching practice can be a valuable source for the implementation of the requirements of educational standards in working with children with intellectual disabilities. The scale implementation of this work is going to be started in Russia in 2016.

Undoubtedly, it would be appropriate to include the theory of abnormal development by Troshin (1915) into the conceptual ideas of inclusive education and other provision:

- recognizing the potential of abnormal mental development of the child;

- reliance on the unity of the laws of normal and abnormal development;

- holistic study of the child.

\section{The Idea of Social Environment in Inclusive Education}

The idea of the role of social environment in the development of the abnormal child can be considered as a methodological value-scientific heritage of Russian scientists of the first quarter of the twentieth century. This 
idea is supported by outstanding Russian physician and educator V. P. Kaschenko (1870-1943), who constantly emphasized that no child should adapt to educational programs and training, but the programs should be adapted to children. In his view, education should take into account the characteristics of each individual child, any back-breaking demands will cause negative scenarios of child's development, abilities and inclinations will be unused or undeveloped. In order to avoid this, according to V. P. Kashchenko (1), it is important to study the child in the fullness of his/her features and personal qualities. V. P. Kashchenko talked about the social importance of correcting the personal disadvantages. Creating an environment where the child's mental powers were freely and fully developing was one of the requirements implemented by the teaching staff of the sanatorium-schools, created with the participation of V. P. Kashchenko.

The value of the environment in the development of the child was recognized by many Russian scientists in the first quarter of the twentieth century. The role of the environment in the intellectual and moral development and education of children and adolescents was noted by I. Sikorsky. He pointed out that the development of the child is directly related to the conditions in which it takes place.

The problem of interaction between the environment and personality was reflected in the works of S. T. Shatsky (1878-1934 years). He noted the role of "favorable environment" of school in the elimination of many barriers to the development of the child's personal experience. The main point is that there is a need in a creation of favorable factors in the society which will become a special pedagogical support for children. Shatsky (1962) saw a special role of the school environment in creation rich emotional and mental life for children. He pointed to the social side of school life, the understanding of it will help to remove the obstacles in child's communication. It is important to notice the succession of ideas S.T. Shatsky in relation to inclusive education theories which prove that the joint training of healthy children and children with developmental disorders is a significant condition for social development of both.

It is impossible not to notice the continuity of Shatsky's ideas in positions developed by the inclusive education theorists who believe that the joint training of healthy children and children with developmental disorders is a significant condition for social development of both.

Another relevant idea of S. T. Shatsky is that it is important to take into account the impact of environmental factors on personality in order to create the conditions favorable for the physical and spiritual development of children. The modern idea of health-saving educational environment can be considered as a dialectical development of S. T. Shatsky's ideas.

The issue of the interaction between environment and the child has got a tremendous development through scientific activity of L. S. Vygotsky. He considered the environment as a source of development of higher mental functions of man, pointing to the fact that child development is not obeyed to biological but to socio-historical laws (Vygotsky, 1993).

Thus, we see that the Russian scientists of the last century paid great importance to the role of the environment in the development of the child. The critical reflection of these views - the prospects for the development of modern teaching practices focused on the realization of equality of educational rights of any child.

The idea of continuous model of inclusive education is based on the Vygotsky's statement that "the process of development dialectically prepares the following and turns, moving into a new type of development" (Vygotsky, 1993). The implementation of the principle of continuity in the system of inclusive education, where there is an opportunity for social interaction between healthy child and child with disabilities, provides the conditions for consistent mastery of the culture of relations with the "other", different from his peers.

One of the main provisions of the cultural-historical theory of Vygotsky is the statement that the qualitative change in the social situation of human activity-the basis of his mental development. Inclusion of the child with disabilities into the environment of joint training and education together with healthy peers is making qualitative changes in the social situation of development. The institutions of inclusive education where children with disabilities can interact with healthy peers who, in turn, gain experience with those who for health reasons is different from them. And, according to the concept L. S. Vygotsky, it is in a situation of social interaction are determinants of human mental development. This development will proceed successfully only when every child will feel safe educational environment adapted to its characteristics and needs. Analysis of the scientific heritage of Vygotsky allows taking an inclusive model of education as one of the ways of cultural development of abnormal child. This path must empower child's social inclusion.

Another statement of cultural-historical theory of Vygotsky which has a positive potential for the development of the idea of inclusive education is the statement that training and education are the principal conditions for the 
human mental development. The thesis that education is the driving force of human development can be applied to all children regardless of their mental and physical health. It involves the creation of the necessary conditions for the training of each child. Just realizing the institution can guarantee the equality of educational rights for all its members, including those with intellectual disabilities (Vygotsky, 1993).

\section{The Ideas of Mental Development in Inclusive Education}

The role of education in the mental development of the child was studied by P. P. Blonsky (1884-1941 years). He studied the relationship between intellectual development and academic success of the child. He wrote: "If the mental development of the child affects the academic success, then, of course, the school affects the mental development" (Blonsky, 1997). Blonsky noted that the school accelerates the pace of children's mental development.

Children with disabilities including those with impaired mental development can gain some impulse in the regular school accelerating the pace of their cognitive development in the case that educational environment will be organized in a right way. Blonsky (1997) also emphasized that "capable pupil" should receive from the teacher not less attention. Undoubtedly, this setting is valuable for inclusive education with the ideas of equality of educational rights for all students, including equal rights to the attention of the teacher. The ongoing dynamics of intellectual development of students can be considered as one of the indicators of the effectiveness of the educational institution.

The problem of mental development of the child and the issue of measuring its results was studied by Russian researchers of the first quarter of the twentieth century. The idea of measurement is closely linked to pedology. The term "pedology" appeared in 1893 thanks to O. Hrisman. The founder of Russian pedology is A. P. Nechaev (1870-1948), who created the first Russian laboratory of experimental educational psychology in 1901. The peculiarities of children's mentality were studied in the laboratory. Nechayev believed that it is impossible to solve the problems of children's education and development without full and complete knowledge of the person (Shvartsman, 1995). Due to his active participation Russian scientists begin to develop pedological tools (tests, questionnaires, questionnaires) that were used to measure intelligence, emotional and behavioral reactions, physical and mental development of the child.

The role of mental development in the teaching determined the search of methods that can measure child's mental abilities. The most successful technique is the method performed by Rossolimo (1914).

Rossolimo, Russian neurologist, psychiatrist and psychologist (1860-1928 years) has developed a method of "psychological profile". The method has brought him worldwide fame. Due to this method 22 mental functions of the individual were studied by him. "Psychological profile" of personality allows determining child's attention, will, memory and thinking. Creation of "psychological profile" allows to assess the level of intellectual development of the child and to orient the work of the teacher on the mental development of the student.

Rossolimo has developed series of tasks for younger students ("Short Rossolimo's method") and preschoolers ("Method of elementary representations of professor Rossolimo"). The method "psychological profile" has a unique value for working with special children. Its practical application allows enhancing the mental development of patients and mentally retarded children during the process of training and education.

Other Russian scientists participated in the development of the test material. In 1901 the Russian community could get acquainted with the tests of A. P. Nechayev intended for researching the playback from memory. Tests can be used as in the group work, also in the individual work. The testees were offered 12 pictures or 12 words which people had to reproduce. Questions of differential diagnosis of the intellectual development of the children were studied by N. P. Postovsky. He participated in the development of methods for the determination of mental retardation of the child.

Analytical understanding of all the measuring instruments, established at the beginning of the last century, has a special significance in connection with the provisions of the "United State of the concept of a special federal standard for children with disabilities." Three levels of school education are identified in the concept. The choice of this level is determined by the capabilities of the child. In order to determine the level of educational opportunities of "special" child the diagnostic methods of the last century can be used.

The practice of measuring the child's characteristics, established at the beginning of the last century, could be applied not only to the scope of one's intellectual development. In the studies of the first quarter of the twentieth century the idea of a holistic study of the child's personality was actively developed. The observation method which studied the mental manifestations of children and their behavior was popularized. Recommendations for the study of the child have been drawn up (A. F. Lazurskiy "Program of researching the personality" and G. I. 
Rossolimo "Plan of studying the child's soul in a healthy and sick state" M., 1909). M. Y. Basov developed the psychological method of observations in the study of mental development of children. In 1910 F. E. Rybakov published "Atlas of experimental psychological study of personality". The tables of Atlas allowed teachers to explore not only the child's ability to perception, attention, one's memory, observation, but also such characteristics as a person's inclinations and suggestibility.

Great contribution to the study of the child's personality was made by V. P. Kacshenko. His program of studying the child's personality consists of five main sections: social and biological conditions of behavior; learning of behaviors (individual and collective); study of the whole person; school success; plan of medical and pedagogical correction program based on the study of the child (Kacshenko, 1994). Variety of methods could be used in order to study the personality of the child, including the testing, monitoring, laboratory and natural experiment, etc.

V. P. Kacshenko also suggested filling up the survey sheet of a child. According to V. P. Kacshenko the survey sheet had to contain the information about the history of the child's mental and physical development, the results of medical, pedagogical and psychological surveys.

The methodological basis of developing study belongs to the ideas of Vygotsky (1931). The zones of current and proximal development were developed by Vygotsky. According to it, during the learning process, in the dialogue and cooperation with adults and peers, the zone of proximal development is created. This postulate determines the relevance of the implementation in the practice of inclusive education the group forms of lessons. Organization of group activities should be built so that the children with disabilities can learn to do something on their own in cooperation with the other children.

Taking into account modern requirements for the organization of pre-school, school and even professional education there is another relevant idea of Vygotsky (1993)-game and gaming activities. Analysis of his works demonstrates the author's vision of the role of the game in the mental development of the child. The scientist emphasizes the importance of the game for the development of abstract thinking, imagination, regulatory frameworks, etc. Many ideas of L. S. Vygotsky about the role of the game can be the basis for the concept of learning in the system of inclusive pre-school and school education.

P. P. Blonsky developed the ideas of organizing the educational process for children with mental retardation, very advanced children, lazy and disrupters. Some works of Blonsky contain a description of the mental activities of children with intellectual disabilities. For example, a scientist observes elementary associations created by them, which may contain a large percentage of meaningless words or words that are not related to the case, including the same word, etc.. These and other knowledge about the peculiarities of the child's mental development during the educational process is a great informational value for the teacher.

Much attention Blonsky (1997) paid to the development of problems of knowledge assimilation by students. In his opinion the factors of students' success are: child's interest in learning the educational material, the level of one's care, health. P. P. Blonsky considered teaching as a complex activity, which is based on the dialectical relationship of the mental processes of perception, memory, thinking and speech. Blonsky claimed that there are changes in relationship between thinking and memory which happen through ages. These changes affect the characteristics of the process of remembering, the teacher can help your child learn the special techniques of memorization (mnemonics). Teacher involvement is particularly important in working with children with developmental disabilities.

Bekhterev (1907) firstly applied a scientific approach to the education of young children: based on the study of infants' movements. This approach showed that the formation of personality begins in the first months of life. Among the fundamental problems of pedagogy Bekhterev called the question of the purpose of education, pointing out that the clarity of the objectives depend on how its implementation. Formation of the education goals of inclusive education system is determined by many factors, among them - especially the educational needs of students, especially the educational environment. A significant means of socialization of children, adolescents and young adults with developmental disabilities is a social and labor education. According to V. M. Bekhterev, social and labor education should provide conditions for "overcoming the contradiction between the general purpose of education and personal development of the child" (Bekhterev, 1907). The main task in the formation of education objectives while working with people with disabilities is to create the conditions to overcome obstacles in getting social and labor values skills by students.

\section{Conclusion}

Due to the researches of such great Russian scientists we could mention the main directions of it: an 
anthropological approach in understanding of inclusive education, based on a comprehensive knowledge about the formation of the human being in a man. Such scientists as V. M. Bekhterev, I. A. Sikorsky, G. Y. Troshin and others studied that aspect.

Another direction is the idea of social environment in inclusive education studied in the researches of L.S. Vygotsky, V. P. Kashchenko, S. T. Shatsky. The key concept here is cultural historical theory of L. S. Vygotsky which shows the qualitative change in the social situation of human activity-the basis of his mental development.

The ideas of mental development in inclusive education are the third main direction of the researches. Its main idea is that children with disabilities including those with impaired mental development can gain some impulse in the regular school accelerating the pace of their cognitive development in the case that educational environment will be organized in a right way

The analysis of the works of the greatest representatives of Russian science of the last century shows that the conceptual ideas, methodological approaches of this period do not lose value from the perspective of the changes taking place in education today. Accumulating and extrapolating theoretical heritage of the past in a modern space transformations, we obtain a significant capital for the development of the theory and practice of inclusive education. Due to these researches we can deeply understand analyse the technologies and methods of inclusive education.

The article has a prospect of further researches in the field of historical and methodological basis of inclusive education in the works of Russian and foreign scientists.

\section{References}

Bekhterev, V. M. (1907). Objective psychology. Saint-Petersburg.

Blonsky, P. P. (1997). Psychology of junior student. Voronezh. 574 p.

Druzhilovskaya, O. V. (2008). Scientific and historical heritage of G.Y. Troshin and its importance for the modern special psychology and pedagogy. Cultural-historical psychology, 3, 11-16.

Kashchenko, V. P. (1994). Pedagogical correction (2nd ed., p. 223).

Munipov, V. M. (1968). Bekhterev V.M. and his role in the history of Russian pedagogical psychology and pedagogy (p. 24). Retrieved from http://elib.gnpbu.ru/text/referat_munipov_behterev_1968/

Rossolimo, G. I. (1914). Psychological profiles of defective pupils (relative to age, gender, the degree of backwardness) (p. 33).

Shatsky, S. T. (1962). Pedagogical works. T.№ 1. Academy of sciences of RSFSR.

Shvartsman, P. Y. (1995). Pedology. Science, 2, 121-139.

Sikorskiy, I. A. (1882). About difficult children in the educational aspect (p. 7). Kiev.

Ushinsky, K. D. (1945). Selected pedagogical works/Person as a subject of educational process (p. 475).

Vygotsky, L. S. (1931). Pedology and science related to it. Retrieved from http://psychlib.ru/mgppu/periodica/Pedologia071931

Vygotsky, L. S. (1993). Pedagogy-Press.

Vygotsky, L. S. (1999). Pedagogical psychology. Pedagogy-Press, Moscow.

\section{Copyrights}

Copyright for this article is retained by the author(s), with first publication rights granted to the journal.

This is an open-access article distributed under the terms and conditions of the Creative Commons Attribution license (http://creativecommons.org/licenses/by/4.0/). 